Management of Bulgarian Military Medical Teams during Operations "Iraqi Freedom" and "Enduring Freedom"

Major Gen. Prof. S. Tonev, MD, $S_{c} D ;{ }^{1}$

Col. S. Chupetlowski, $M D, P h D ;^{2} D$. Tunkova ${ }^{3}$

1. President, Military Medical Academy (MMA), Surgeon General of the Bulgarian Armed Forces, Sofia, Bulgaria

2. Chief, Military Medical Detachment for Emergency Response, MMA, Sofia, Bulgaria

3. Expert in Military Logistics, Military Medical Detachment for Emergency Response, MMA, Sofia, Bulgaria

Objective: After Bulgaria became a member of the Allied Forces, the Bulgarian Military Medical Service (Military Medical Academy) utilized the North Atlantic Treaty Organization (NATO) medical concept for treating battlefield trauma. The purpose of this presentation is to evaluate the process of composition, education, training, and control on military medical teams (for R1 and R2 medical treatment facilities (MTF)) and to share some experiences. Methods: From 2002 to mid-2009, during operations "Iraqi Freedom" and "Enduring Freedom", Bulgarian Armed Forces sent 28 medical teams to Role 1 and 35 surgical teams to Role 2 MTFs. These teams participated in the treatment of large number of patients, including 590 battlefield trauma cases. The processes of preparation and training of the surgical teams was analyzed.

Results: The proposed methodology considers selection, certification, deployment, and control of the medical personnel from R1 and R2 MTFs. The authors shared their own experience according using different methods to improve the training activities. The special issues of medical support during operations are discussed-multinational climate, specific surgical problems, psychological impact of military environment, etc. The specific character of the surgical management in the International Security Alliance Force camps is described.

Conclusions: Several general conclusions are made considering different aspects of the management of Bulgarian military medical teams during Operations Iraqi Freedom and Enduring Freedom.

Keywords: Bulgaria; Iraq; medical team; military; Operation Enduring Freedom; Operation Iraqi Freedom

Prehosp Disaster Med

Five-Year Experience with Battlefield Trauma Management at Role 2 Military Field Hospitals in Afghanistan

Col. S. Chupetlowski, $M D, P h D ; 1$

Major Gen. Prof. S. Tonev, MD, ScD; $;^{2}$. Spasov, $M D^{3}$

1. Chief, Military Medical Detachment for Emergency Response, Military Medical Academy, Sofia, Bulgaria

2. President, Military Medical Academy (MMA), Surgeon General of the Bulgarian Armed Forces, Sofia, Bulgaria

3. Head of Surgical Department, Military Medical Detachment for Emergency Response

Objective: The objective of this study was to analyze Bulgarian surgical experience with severe battlefield trauma management during operations in Afghanistan.

Methods: In this study, the authors presented their experience based on battlefield trauma cases treated by Bulgarian military surgical teams at Role 2 military field hospitals. The material consists of various battle traumas affecting all anatomical regions. The information comes from the trauma registries of the field hospitals.

Results: A total of 243 trauma patients were managed during a five-year period. Patients were placed into one of two groups: (1) ballistic and explosive trauma; and (2) other trauma occurring during armed conflict. The ballistic trauma patients group consisted of 128 patients with a single injury, and three with multiple wounds. The explosive trauma group consisted of 105 patients, including: (1) penetrating trauma, 87; (2) blunt trauma, 4; (3) single barotraumas, 2 ; and (4) combined trauma, 12 . The other trauma group consisted of two penetrating and five blunt trauma patients. Conclusions: During armed conflicts, surgical management at Role 2 hospitals includes not only ballistic and explosive trauma, but also other trauma provoked via incidents other than battlefield wounding. The explosive trauma group consisted of $45 \%$ of all trauma cases managed during a five-year period.

Keywords: Afghanistan; battlefield; field hospitals; military; trauma management

Prehosp Disaster Med

\section{Collaboration between Military and Civilian Systems in Managing Emergencies}

Tonisav Antoljak; Ante Zvonimir Golem; Tomo Kovaä; Ivan Dobrif; Slavko Davila

Clinical Hospital Center, Zagreb, Croatia

Introduction: As soon as declaring independence in 1991, Croatia faced the unexpected military and paramilitary agression of the former Yugoslavian federal army. Since there was no aid from abroad, the country had to rely on its own capabilities to cope with the increasing health demands among soldiers and civilians, including the abrupt migration of $16 \%$ of the population from the war area. This was done during circumstances involving obstructed traffic, massive destruction of houses and towns, considerable loss of healthcare infrastructure and supplies on occupied territory, as well as with most of hospitals under direct fire.

Methods: Mobile Surgical Teams composed of civilian medical staff were sent to the first battleline. They treated wounded persons, but their main responsability was to provide regular health care to civilians in the vicinity. Special services were developed for other public health problems and their activities were coordinated by Headquarters for Medical Crisis.

Results: During the war in Croatia, $64.5 \%$ of wounded persons were supported by organized first aid, among them $90 \%$ in the presence of physician. More than 30,000 people were treated, among them $68 \%$ in war hospitals with a transport time less then one hour for $61 \%$. Normal water and food supply was assured, there were no epidemics, and sporadic infectious diseases were recognized and cured. No tetanus infections and few cases of gas gangrene were registered.

Conclusions: The integration of disaster preparedness must be brought to the local level. Hospitals must maintain operational effectiveness with minimal interruptions despite the potential loss of infrastructure and personnel. Surgeons are 